\title{
Temperature Induced Voltage Offset Drifts in Silicon Carbide Pressure Sensors
}

\author{
R.S. Okojie ${ }^{\mathrm{a}}$, D. Lukco ${ }^{\mathrm{b}}$, V. Nguyen ${ }^{\mathrm{c}}$, and E. Savrun ${ }^{\mathrm{c}}$ \\ ${ }^{a}$ NASA Glenn Research Center, Cleveland, OH, USA \\ ${ }^{\mathrm{b}}$ ASRC Research Corp., NASA Glenn Research Center, Cleveland, OH, USA \\ 'Sienna Technologies, Inc. Woodingville, WA, USA \\ atelephone: 216-433-6522, email: robert.s.okojie@nasa.gov
}

\begin{abstract}
We report the reduction of transient drifts in the zero pressure offset voltage in silicon carbide (SiC) pressure sensors when operating at $600{ }^{\circ} \mathrm{C}$. The previously observed maximum drift of $\pm 10 \mathrm{mV}$ of the reference offset voltage at $600{ }^{\circ} \mathrm{C}$ was reduced to within $\pm 5 \mathrm{mV}$. The offset voltage drifts and bridge resistance changes over time at test temperature are explained in terms of the microstructure and phase changes occurring within the contact metallization, as analyzed by Auger electron spectroscopy and field emission scanning electron microscopy. The results have helped to identify the upper temperature reliable operational limit of this particular metallization scheme to be $605{ }^{\circ} \mathrm{C}$.
\end{abstract}

Keywords: Silicon carbide, high temperature, pressure sensor, offset voltage drift, stability.

\section{Introduction}

Silicon carbide (SiC) is the choice semiconductor material for use as pressure sensors for extreme temperature applications $\left(\sim 600{ }^{\circ} \mathrm{C}\right)$, as has been previously demonstrated [1]. Compared to silicon, it has wider band gaps (2.9-3.2 eV, depending on polytype), near inert surface chemistry, superior thermomechanical properties, and functional piezoresistivity that extends beyond $600{ }^{\circ} \mathrm{C}[2,3]$. However, existing long term reliability challenges, largely due to drifting zero pressure offset voltage, $V_{o z}$, have prevented its permanent insertion into operational systems. Previous efforts have been made to understand the mechanisms of drifting $V_{o z}$ during high temperature operation with the goal of developing more stable and operationally functional pressure sensors [4-6]. The $V_{o z}$ drift is unpredictable, which does not lend itself to active correction or temperature compensation. The drift becomes increasingly severe as sensors are pushed to operate in higher temperature regimes, leading to excessive measurement errors. These reports provided evidence that an expanded modification of the contact metallization stack with an increased number of diffusion barrier layers successfully reduced the drift. Because this $V_{o z}$ drift phenomenon is largely driven by thermodynamic activities and reaction kinetics that are associated with the conducting elements that constitute the metallurgical junction with the semiconductor contact region, its resolution will require the stabilization of these mechanisms [7, 9]. Since it is desired to operate the pressure sensor at $600{ }^{\circ} \mathrm{C}$ and higher, it will require the utilization of materials that have near inert surface chemistry and metallization schemes that promote stable ohmic contact, limit intermetallic diffusion and phase formations, and are less susceptible to oxidation. Essentially, the active thermodynamic and kinetic drivers must be stabilized.

In this new report, we evaluated several $\mathrm{SiC}$ pressure sensors having the same metallization scheme at different temperature regimes to determine how the drift responds to temperature. The goal is to identify the upper operational temperature threshold of the sensors in the context of the current metallization scheme.

\section{Sample preparation}

Piezoresistive pressure sensors were fabricated in an n-type $4 \mathrm{H}-\mathrm{SiC}$ epilayer that was homoepitaxially grown on a semi-insulating $4 \mathrm{H}-\mathrm{SiC}$ wafer. Such a SiC-on-Insulator configuration ensures sensor operation beyond $600{ }^{\circ} \mathrm{C}$ with minimal junction leakage current. For the contact metallization, the piezoresistors were initially metallized with a stack of $\mathrm{Ti}(150 \mathrm{~nm}) / \mathrm{TaSi}_{2}(400$ $\mathrm{nm}) / \mathrm{Pt}(300 \mathrm{~nm})$, as illustrated in Fig 1(a). After photolithographic pattern definition the Pt layer was etched in 10:9:1 mixture of $\mathrm{H}_{2} \mathrm{O}: \mathrm{HCl}: \mathrm{HNO}_{3}$ (aqua regia) at $67{ }^{\circ} \mathrm{C}$ for 8 minutes, then $70{ }^{\circ} \mathrm{C}$ for 35 seconds to create four contacts on the piezoresistors. This was the standard scheme used previously that did not completely prevent Au diffusion to the SiC interface, which compromise the integrity of the $\mathrm{Ti}$ ohmic contact to $\mathrm{SiC}[5,6]$. In this present work, it was necessary to increase the contact metallization stack with alternating layers of $\mathrm{TaSi}_{2}$ and $\mathrm{Pt}$, which, upon reacting to form multiple PtSi layers, would create an effective diffusion barrier against $\mathrm{Au}$ to the $\mathrm{SiC}$ interface. Therefore, another layer of $\mathrm{TaSi}_{2}(400$ $\mathrm{nm})$ was deposited, at which point the underlying 
$\mathrm{TaSi}_{2}$ and the top $\mathrm{TaSi}_{2}$ encased the etched Pt layer. This was followed by another contact pattern definition of the top $\mathrm{TaSi}_{2}$ to align with the buried etched Pt layer. Etching of the now $800 \mathrm{~nm}$ field $\mathrm{TaSi}_{2}$ and $150 \mathrm{~nm} \mathrm{Ti}$ was performed with buffered oxide etch, followed by the first furnace anneal at $650{ }^{\circ} \mathrm{C}$ for 30 minutes in 5 slpm Ar ambient (see Fig. 1a). This anneal process formed the Ti ohmic contact to $\mathrm{SiC}$ and also $\mathrm{TaSi}_{2} / \mathrm{Pt} / \mathrm{TaSi}_{2}$ zone reactions to form two layers of platinum silicide diffusion barriers against potential Au diffusion from the top.

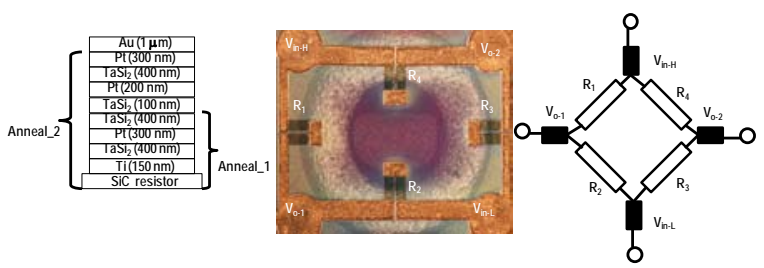

(a)

(b)

(c)

Fig. 1: a) Contact metallization used consisted of alternating layers of $\mathrm{TaSi}_{2}$ and $\mathrm{Pt}$; b) The pressure sensor top structure shows the location of the contact metallization on the terminals; c) The equivalent Wheatstone bridge circuit of the sensor and the corresponding contact terminals and piezoresistors.

Another deposition of $\mathrm{TaSi}_{2}(100 \mathrm{~nm}) / \mathrm{Pt} \quad(200$ $\mathrm{nm}) / \mathrm{TaSi}_{2}(400 \mathrm{~nm}) / \mathrm{Pt}(300 \mathrm{~nm})$ was performed, which was followed by a $2 \mu \mathrm{m}$ aluminum (Al) deposition. Contact pattern was defined in $\mathrm{Al}$ and etched in $\mathrm{H}_{3} \mathrm{PO}_{4}$ at $50{ }^{\circ} \mathrm{C}$ for 4 minutes. The $\mathrm{Al}$ was used as etch mask to etch the $\mathrm{TaSi}_{2}(100 \mathrm{~nm}) / \mathrm{Pt}(200$ $\mathrm{nm}) / \mathrm{TaSi}_{2}(400 \mathrm{~nm}) / \mathrm{Pt}(300 \mathrm{~nm})$ stack by reactive ion etching under the following set of conditions: $\mathrm{Ar}=140$ sccm, SF6 $=5$ sccm, Pressure $=25 \mathrm{mT}$, and Power $=300$ Wrf. The residual Al etch mask was stripped in $\mathrm{H}_{3} \mathrm{PO}_{4}$ and the wafer underwent a second furnace anneal as described above. Finally, Au deposition was performed, followed by bond pad definition and etching in $\mathrm{H}_{2} \mathrm{O}: \mathrm{HCl}: \mathrm{HNO}_{3}$ at $40{ }^{\circ} \mathrm{C}$ for 2 minutes. The Au was used to prevent the diffusion of oxygen from the top surface. The wafer was diced into individual chips, as shown in Fig. 1(b), and some known good ones were selected and packaged. The maximum temperature during the packaging processes was $750{ }^{\circ} \mathrm{C}$ for a total of 30 minutes. The circuit schematic of the $\mathrm{SiC}$ pressure sensor depicting the closed Wheatstone bridge configuration used in the evaluation is shown in Fig. 1(c).

\section{Sensor Evaluation}

The packaged sensors were divided into three batches, with each batch evaluated at different temperatures. Sensors 195 and 196 were initially soaked between $700{ }^{\circ} \mathrm{C}$ and $735{ }^{\circ} \mathrm{C}$ for 24 hours, followed with a longer thermal soak at $635{ }^{\circ} \mathrm{C}$. Sensors 197-199 were soaked at constant temperatures between $680{ }^{\circ} \mathrm{C}$ and $700{ }^{\circ} \mathrm{C}$ and sensors 200-202 between $605{ }^{\circ} \mathrm{C}$ and $615{ }^{\circ} \mathrm{C}$. The temperature spreads were due to the non uniform temperature distribution in the oven. During thermal soaking, the resistances of individual piezoresistive sensing elements on the Wheatstone bridge configured sensors were measured with a Keithley $270 \mathrm{~A}$ I-V curve tracer when appreciable changes in the $V_{o z}$ were observed. The $V_{o z}$ was digitally acquired during thermal soak every 20 minutes. By measuring the resistance at key times, a correlation could be drawn between the transient $V_{o z}$ drift and resistance changes. It could then be directly associated with the thermodynamic and kinetic reactions occurring within the contact metallization.

In a parallel evaluation, five unpackaged sensors from the same wafer were used as trackers for failure analyses after thermal treatment. All five tracker sensors were initially annealed at $750{ }^{\circ} \mathrm{C}$ in air for 30 minutes to simulate the maximum temperature during packaging. This was followed by thermal treatment under conditions similar to the packaged 202 sensor. One tracking sensor was extracted from the oven whenever a large relative change in the $V_{o z}$ of a packaged sensor was observed. The key difference between the tracking sensors and packaged sensors was that the contact metallization of the former was exposed to oven atmosphere while the contact metallization of the latter was in a hermetically sealed package. This meant that the tracking sensors experienced the worse case conditions.

\section{Results and Discussions}

The circuit schematic of the $\mathrm{SiC}$ pressure sensor depicting the closed Wheatstone bridge configuration used in the evaluation is depicted in Fig. 1(c). The $V_{\text {oz }}$ plots of sensors 195-196, 197-199, and 200-202 as functions of time at elevated temperatures are shown in Figs. 2(a), (b), and (c), respectively. Sensors 195-196 were initially soaked at between 700 and $735{ }^{\circ} \mathrm{C}$ for the first 24 hours, after which the temperature was dropped to $635{ }^{\circ} \mathrm{C}$ for the remaining duration of the test. These two sensors, as indicated by the large changes of $V_{o z}$ shown in Fig. 2(a), failed within the first few hours. Sensors 197 and 199 that were treated between 680 and $700{ }^{\circ} \mathrm{C}$ also failed, but a little later ssee Fig. 2(b) $\}$. While the $V_{o z}$ of sensor 199 did not run away, it, however, went through large swings and stability was never achieved. Failure was manifested by the gradual non-linearity observed in the $\mathrm{I}-\mathrm{V}$ characteristics in all the five sensors in the course of time. In contrast, the recorded $V_{o z}$ drift of sensor 200 $\left(615{ }^{\circ} \mathrm{C}\right.$ ) after 450 hours was $25 \mathrm{mV}$ before rolling 
off to failure \{see Fig 2(c)\}. The time of failure of this sensor coincided with the rapid increase of the bridge resistance, as seen in Fig. 3(a). Ideally, a flat $V_{o z}$ response is achieved if the four resistors, $R_{1}$ to $R_{4}$, remain relatively unchanged at temperature. The smallest deviation from previous values is reflected as drift in the $V_{o z}$. In the case of sensor $201\left(612{ }^{\circ} \mathrm{C}\right)$, the maximum $V_{o z}$ drift was $30 \mathrm{mV}$ after 450 hours, beyond which it gradually increased. The resistortime characteristics shown in Fig. 3(b) indicated small changes up to 450 hours, after which a higher rate of increase was observed. This transition point, for all practical purposes, coincided with the upward
$V_{o z}$ drift seen in Fig. 2(c). Sensor $202\left(605{ }^{\circ} \mathrm{C}\right)$ offered the most promising result in that the maximum $V_{o z}$ drift after 450 hours was about $10 \mathrm{mV}$, and slightly above $15 \mathrm{mV}$ after 700 hours. The result is also reflected in the characteristics of the bridge resistance elements seen in Fig. 3(c), which showed smaller relative changes from previous values compared to sensors 200 and 201. Based on prior reported results [4-6], it is believed that the improved performance of sensor 202 was due to the fact that it experienced the lowest temperature $\left(605^{\circ} \mathrm{C}\right)$.

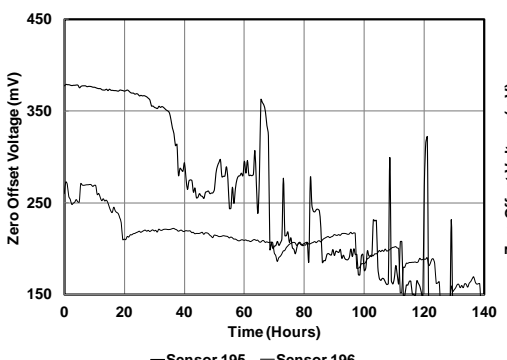

(a)

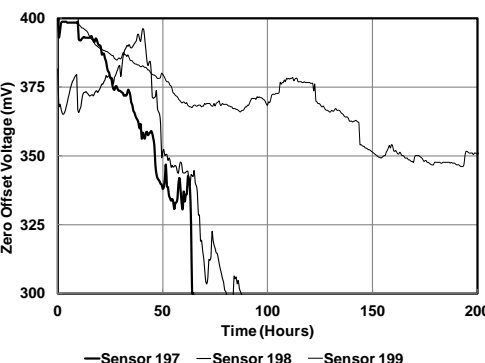

(b)

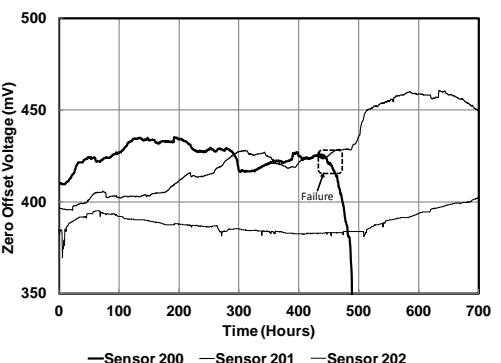

(c)

Fig. 2: Offset voltage drift characteristics of a) sensors 195 and 196 between $700{ }^{\circ} \mathrm{C}$ and $735{ }^{\circ} \mathrm{C}$ for 24 hours before dropping to $635{ }^{\circ} \mathrm{C}$, b) sensors $197-199$ between 680 and $700{ }^{\circ} \mathrm{C}$, c) sensors $200-202$ between $605^{\circ} \mathrm{C}$ and $625^{\circ} \mathrm{C}$.

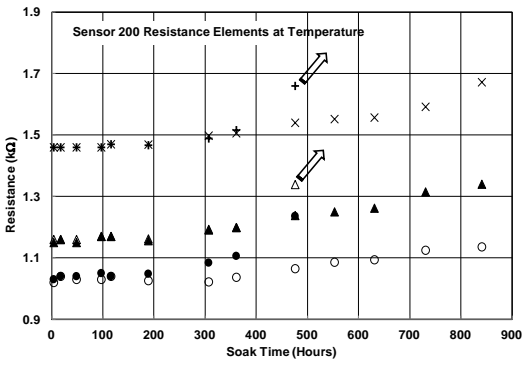

$\Delta R 1 \bullet R 2 \quad J R 3 \quad$ R4 $\times$ Rout + Rir

(a)

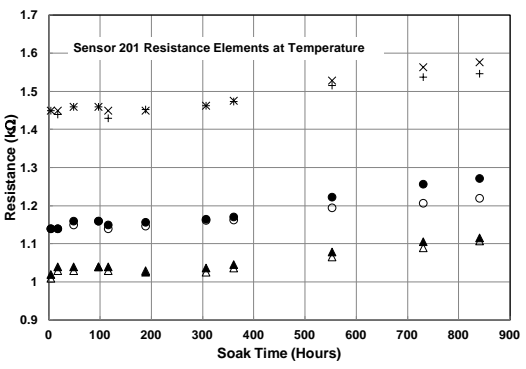

(b)

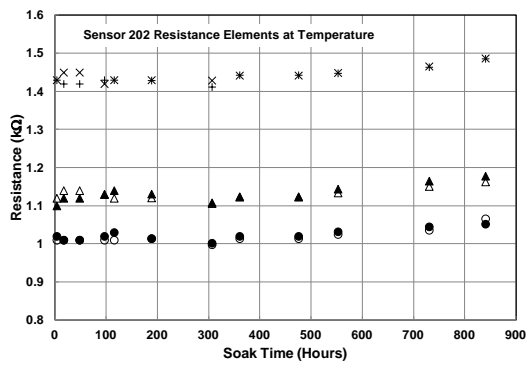

(c)

Fig. 3: Wheatstone bridge resistance values measured at between $605{ }^{\circ} \mathrm{C}$ and $615{ }^{\circ} \mathrm{C}$ of a) sensor 200, b) sensor 201, and c) sensor 202. Degradation of resistance occurred earlier as temperature increased.

\section{Failure Analyses}

The Auger electron spectroscopy (AES) depth profile analysis of the unpackaged tracking sensor initially annealed at $750{ }^{\circ} \mathrm{C}$ is shown in Fig. 4(a), and the corresponding field emission scanning electron microscopy (FE-SEM) image of the contact cross section in Fig. 4(b). From the AES analysis, the PtSi zone reactions are well defined. No significant $\mathrm{Au}$ migration through the first PtSi layer is observed, thus further confirming the diffusion barrier property of PtSi against Au reported earlier [4, 5]. The observed oxygen peak at about $1600 \mathrm{~nm}$ was due to a thin oxide layer that formed after the first furnace anneal. The oxygen peak coincides with the dark line seen in the cross section FE-SEM image of Fig. 4(b). After $400 \mathrm{hrs}$ at $605^{\circ} \mathrm{C}$, another tracking sensor was extracted from the oven and analyzed, the AES and FE-SEM results of which are shown in Fig. 5(a) and (b), respectively. As expected, the diffusion of oxygen from the top surface was blocked by $\mathrm{Au}$ while the diffusion of Au was prevented by the

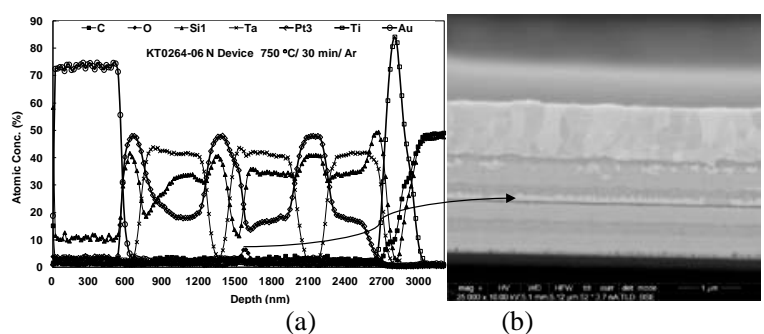

Fig. 4: a) The AES analysis of the tracking sensor initially annealed at $750{ }^{\circ} \mathrm{C}$ and b) corresponding FE-SEM image. The arrow indicates potential oxygen path created due to process error. 


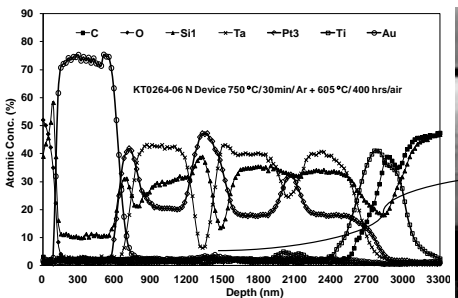

(a)

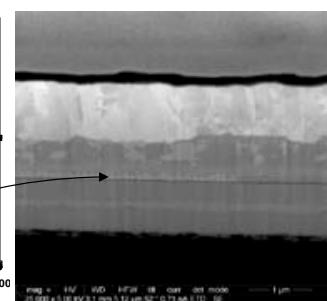

(b)
Fig. 5: a) The AES analysis of the tracking sensor initially annealed at $750{ }^{\circ} \mathrm{C}$ and after 400 hrs at $605{ }^{\circ} \mathrm{C}$, and b) corresponding FE-SEM image.

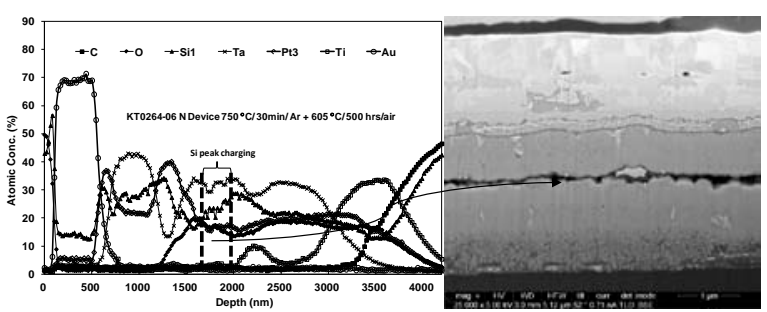

(a)

(b)

Fig. 6: a) The AES analysis of the tracking sensor initially annealed at $750{ }^{\circ} \mathrm{C}$ and after $500 \mathrm{hrs}$ at $605{ }^{\circ} \mathrm{C}$. Oxygen and Pt migration to the $\mathrm{SiC}$ interface are observed; b) corresponding $\mathrm{FE}$ SEM image shows delamination induced stress by oxidation between $\mathrm{TaSi}_{2}$ layers. High density of grain boundaries are observed in the bottom metal stack. No significant microstructural changes are seen in the top set of metallization stack.

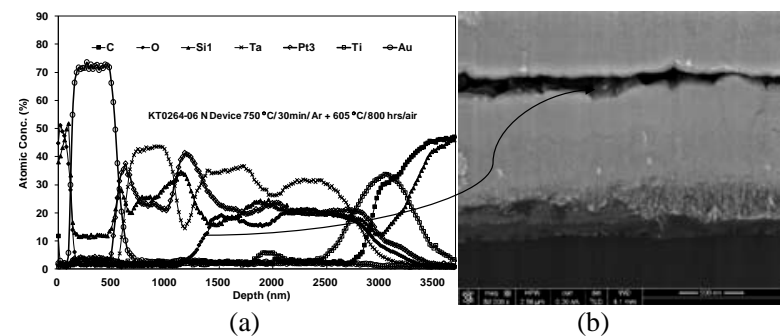

Fig. 7: a) The AES analysis of the tracking sensor initially annealed at $750{ }^{\circ} \mathrm{C}$ and after 800 hrs at $605{ }^{\circ} \mathrm{C}$, and b) corresponding FE-SEM image. Further oxidation induced stress reveals film warpage and interlayer delamination. Also present is the high density of grain boundaries in the bottom metal stack.

topmost PtSi barrier layer. The oxygen peak in the film previously observed in Fig. 4(a) has broadened due to tailing caused by sample roughness. The migration of Pt toward the SiC interface is observed. After 500 hours, however, the analyses of another tracking sensor revealed dramatic changes in the elemental concentration and film microstructure, as can be seen in Figs. 6(a) and (b) of the AES and FESEM, respectively. A high concentration of oxygen is observed to grow at the interface between the first deposited $\mathrm{TaSi}_{2}$ and Pt layers. A review of fabrication process steps revealed that an over etching error at that interface resulted in the infiltration of oxygen between the layers, after which subsequent oxidation during thermal treatment induced stresses in the films that resulted in the observed warpage and delamination. From this interface oxidation proceeded both inwardly and outwardly, but the latter progression was eventually stopped while the former continued toward the SiC interface. There was no mechanism in place to promote the outward oxidation, since the immediate layer above is less susceptible to oxidation. Also dramatic microstructural changes had occurred in the metallization between 400 and 500 hours, specifically within the initially deposited $\mathrm{Ti} / \mathrm{TaSi}_{2} / \mathrm{Pt}$ stack. In contrast to the relatively well defined reaction zones after 400 hours, as seen in Fig. 5, the elemental characteristics and the microstructure texture seen in Fig. 6 after 500 hours revealed significant intermixing, high density of grain boundaries, and out diffusion of free $\mathrm{Ti}$. The out diffusing free $\mathrm{Ti}$ was the result of the gradual decomposition of $\mathrm{Ti}_{5} \mathrm{Si}_{3}$ by inward migrating Pt. The eventual interaction between $\mathrm{Ti}$ and oxygen through grain boundaries would certainly accelerate the oxidation process inward. Therefore, considering the coincidence in time between when the changes in the contact microstructure occurred and when the sensor resistances and $V_{o z}$ drift values started increasing at higher rates, the failure could be partially attributed to the oxidation process. Also, between 400 and 500 hours excess $\mathrm{Pt}$ had migrated close to the $\mathrm{SiC}$ interface. The presence of platinum silicide at the ntype $\mathrm{SiC}$ interface is known to cause rectification or non-linear behavior, considering that the work functions of silicides of platinum are higher than the work function of n-type $\mathrm{SiC}[10,11]$.

It is evident that the presence of oxygen and Pt at or near the SiC interface between 400 and 500 hours coincided with the accelerated changes in the bridge resistance and the $V_{o z}$ that were observed. After 800 hours, little change was observed in the AES and FE-SEM profiles, as seen in Figs. 7(a) and (b), respectively. Remarkably, the diffusion of $\mathrm{Au}$ was prevented during the entire test duration by the topmost layer of PtSi. Also of significance was the prevention of oxygen diffusion into the contact from the top by Au.

\section{Conclusion}

Based on the resistance measurements and materials analyses, a correlation was established between changes in the zero pressure offset voltage, bridge resistance, and temperature. For the metallization scheme used in this work, it was shown that the transient drift in the offset voltage decreased with decreasing temperature. It also revealed that the stability of the sensors is strongly tied to the thermodynamic activities occurring within the sensor metallurgical reaction zones and at the $\mathrm{SiC}$ interface. The migration of oxygen and $\mathrm{Pt}$ toward the SiC 
interface was determined to be the primary failure mechanism. The effects of these mechanisms were manifested electrically by the gradual non-linearity observed in the resistor I-V characteristics over time at temperature. It is believed that the magnitude of the drifts would be less in the absence of the fabrication process error that introduced oxygen. While efforts are underway to reduce the drift further, the upper operating temperature limit for this metallization is considered to be $605{ }^{\circ} \mathrm{C}$.

\section{Acknowledgement}

This work was funded by the Supersonic Project of the NASA Fundamental Aeronautics Program and the Environmentally Responsive Aviation Program.

\section{References}

1. A. A. Ned, R. S. Okojie, and A. D. Kurtz, " $6 \mathrm{H}-$ $\mathrm{SiC}$ Pressure Sensor Operation at $600^{\circ} \mathrm{C}$," Proceedings, $4^{\text {th }}$ International High Temperature Electronics Conference, pages 257-260. 1998.

2. J. S. Shor, L. Bemis, A. D. Kurtz, "Characterization of Monolithic n-Type 6H-SIC Piezoresistive Sensing Elements," IEEE Transactions on Electron Devices, Vol. 41, no. 5, pages 661-665. 1994.

3. R. S. Okojie, A. A. Ned, A. D. Kurtz, and W. N. Carr, "Characterization of Highly Doped n- and p-Type 6H-SiC Piezoresistors.” IEEE Transactions on Electron Devices, Vol. 45, no. 4, pages 785-790. 1998.

4. R. S. Okojie, V. Nguyen, E. Savrun, and D. Lukco, "Improved Reliability of SiC Pressure Sensors for Long Term High Temperature Applications," $16^{\text {th }}$ International Conference on Solid-State Sensors, Actuators and Microsystems, pages 2875-2878. 2011.
5. R. S. Okojie, D. Lukco, C. Blaha, V. Nguyen, and E. Savrun, "Zero Offset Drift Suppression in $\mathrm{SiC}$ Pressure Sensors at $600{ }^{\circ} \mathrm{C}$," IEEE Sensors, pages 2269-2274. 2010.

6. R. S. Okojie, P. Nguyen, V. Nguyen, E. Savrun, D. Lukco, J. Buehler, and T. McCue, "Failure Mechanisms in MEMS Based Silicon Carbide High Temperature Pressure Sensors,” Proceedings $45^{\text {th }}$ IEEE International Reliability physics symposium, pages 429-432. 2007.

7. Y. Sun, X. Sun, B. Sun, and Q. Meng, "Electric Drift of the Bridge Offset for Pressure Sensors and its Utilization," Sensors and Actuators A: Physical, Vol. 58, pages 249-257, 1997.

8. A. Boukabache, P. Pons, G. Blasquez, and Z. Dibi, "Characterisation and Modelling of the Mismatch of TCRs and Their Effects on the Drift of the Offset Voltage of Piezoresistive Pressure Sensors," Sensors and Actuators A: Physical, Vol. 84, pages 292-296. 2000.

9. A. Andrei, C. Malhaire, S. Brida, and D. Barbier, "Long-term Stability of Metal Lines, Polysilicon Gauges, and Ohmic Contacts for HarshEnvironment Pressure Sensors," IEEE Sensors Journal, IEEE, Vol. 6, pages 1596-1601. 2006.

10. J. L. Freeouf, "Silicide Schottky barriers: An elemental description," Solid State Communication, Vol. 33, pages 1059-1061. 1980.

11. J. Pelletier, D. Gervais, and C. Pomot, "Application of Wide-gap Semiconductors to Surface Ionization: Work Functions of AIN and Sic Single Crystals.” J. Appl. Phys., Vol. 55 No. 4, pages 994-1002. 1984. 